\title{
Study of Pesticides Residues in Strawberry Fruits Collected from Major Producing Governorates in Egypt
}

\author{
Salim, Y. M. M., E. E. Nour El-Deen, and A. M. K. Nassar* \\ Pesticides Chemistry and Toxicology, Plant Protection Department, Faculty of Agriculture, Damanhour University, \\ Damanhour, El-Beheira PO Box 59, Egypt
}

Received: $21 / 2 / 2019$

\begin{abstract}
Strawberry is an important crop in Egypt. It's been bombarded with tones of pesticides to control various insects and pathogens. In the present study, pesticides residues were evaluated in strawberry samples that collected from different places, El-Beheira (Al-Nubaryia, Al-Mahmoudia, and Bader cities), El-Minofyia, and Ismailyia Governorates. Pesticides residues were extracted and cleaned up with QuEChERS (quick, easy, cheap, effective, rugged, and safe) method. Then extracts were analyzed with GC-MS to determine the pesticide residue levels. Results showed that the average recovery percentages \pm relative standard deviation (RSD) of pesticides from fortified strawberry samples ranged from $91.7 \pm 4.6$ to $102.1 \pm 5.2 \%$ and $92.8 \pm 6.2$ to $102.3 \pm 4.0 \%$ at 0.1 and $1 \mu \mathrm{gL}^{-1}$, respectively. Residue levels of boscalid, p,p-DDD, and propiconazole pesticides in strawberry samples from Bader city were 5.000, 0.104, and 0.048 $\mathrm{mgKg}^{-1}$, respectively. Endrin and propiconazole residue levels were detected in samples from El-Minofyia city at 0.098 and $0.038 \mathrm{mgKg}^{-1}$, respectively. On the other hand, Propiconazole residues were found in all strawberry samples from the five locations under investigation. Residues of detected pesticides were less than their corresponding maximum residue limits of European Union (EU-MRLs) that highlight the safety of marketed strawberry for Egyptian consumers.
\end{abstract}

Keywords: Pesticide Residues, Strawberry, QuEChERS, GC-MS, Endrin, Propiconazole, Boscalid

\section{INTRODUCTION}

Strawberry is an important cash horticultural crop in Egypt with about 5 and $75 \%$ of the World and African production, respectively (FAO 2018). It is an important cash fruit for Egyptian exporters. Most importantly, it is a rich source of vitamins $\left(A, B_{1}\right.$, $\mathrm{B}_{2}, \mathrm{~B}_{6}, \mathrm{C}$, and $\mathrm{E}$ ), minerals (Fe, $\mathrm{Ca}, \mathrm{P}, \mathrm{Zn}, \mathrm{Cu}, \mathrm{K}, \mathrm{Mn}$, $\mathrm{Na}$, and $\mathrm{Se}$ ), carbohydrates, fiber, protein, organic acids, and polyphenols (anthocyanins, anthocyanidins, carotenoids, flavonoids, furan fatty acids, and hydroxybenzoic and hydroxycinnamic acids) (Belitz et al. 2009). Therefore, consumption of strawberry provides human with numerous health benefits against cardiovascular, neurodegenerative, aging, obesity, and cancer (Saber et al., 2016). Although it's highly popular fruit among consumers, it's been bombarded with tonnes of pesticides to control various pathogens including insects, mites, fungi and bacteria (Zalom et al., 2006).

Accordingly, monitoring pesticides residues in strawberry has been conducted routinely on national and international basis. Most of results confirmed with the presence of elevated levels of pesticides in strawberry compared to the permitted amounts (Belitz et al., 2009). For example, chlorfluazuron, penconazole, and pyrimethanil insecticides were in greater amounts, while $\alpha$ - and $\beta$-endosulfan, chlorpyrifos, carbofuran, triadimenol I and II, captafolmetabolite, and iprodione were less than maximum residue limits (MRLs) in strawberry samples that were collected from Gaza Governorates and measured using GC-MS (Safi et al., 2002). Myclobutanil, dichlorvos, and fenarimol were detected out of 350 pesticides searched for in strawberry among other produce samples (Ueno et al., 2003). In a multi-country surveillance study, 593 samples of strawberry were analyzed for pesticides residues: $93 \%$ of them confirmed with pesticides residues with cyprodinil, fludioxonil, fenhexamid, tolylfluanid, and azoxystrobin being the most detected (Looser et al., 2006). In a 10 years residue monitoring study in Brazil, carbendazim and chlorpyrifos were the detected pesticides in 992 samples of strawberry with levels exceeding the MRLs (Jardim and Caldas, 2012). Chlorpyrifos, chlorpyrifosmethyl, L-cyhalothrin, and profenofos concentration in strawberry were equal to or greater than EU-MRLs (Ahmed et al., 2014). Similarly, pyrimethanil, cyprodinil, fludioxonil, and boscalid were the most detected pesticides in great amounts compared to the tolerable limits (Sójka et al., 2015). However, residues of pesticides in strawberry were reported to be negligible for pyrimethanil (Malhat et al., 2014) and hexythiazox (Saber et al., 2016).

Pesticides residues analysis depends mainly on the employed methods for extraction and determination. Primarily, the extraction technique of pesticide residues is critical (Lehotay, 2011). Therefore, the majority of researchers and certified agencies recommend the usage of QuEChERS (quick, easy, cheap, effective, rugged, and safe)method for extraction and cleanup (Anastassiades et al., 2003c; Frenich et al., 2008; Lehotay, 2011; Schreiber et al., 2013; Sójka et al., 2015). The QuEChERS extracts were analyzed by LC-MS, LC-MS/MS, GC-MS (EI, CI, TOF), GC-ECD and GC-NPD (Looser et al., 2006). Gas chromatography with nitrogen-phosphorus and flame photometric detection was used to estimate nitrogen- and phosphorus-containing pesticide residues in vegetables (Anastassiades et al., 2003c; Ueno et al., 2003). Gas chromatography coupled with mass spectrometry (GC-MS, GC/MS/MS) technique is widely used technique to estimate multi residues of pesticides (52 compounds) in strawberry (Bolanos et al., 2007). Also, UPLC-MS/MS after QuEChERS extraction was effective in the determination of 53 pesticide residues in various samples including 
strawberry (Frenich et al., 2008). A validated GC/MS/MS method was applied after QuEChERS extraction of 151 pesticide residues in strawberry. Also, about 27, 143, and 600 pesticides were measured directly using LC-MS/MS, low pressure GC-tandem mass spectrometry (LP-GC-MS/MS), and targeted and untargeted analysis using two-dimensional gas chromatography time-of-flight mass spectrometry (GC $\times$ GC-TOF-MS), respectively (Fernandes et al., 2014). The UHPLC and GC-MS were employed in the survey of 121 samples for pesticide residues in Poland (Sójka et al., 2015).

Consequently, contamination of strawberry fruits with pesticides residues raises serious health concerns for consumers. Therefore, observing residue amounts must beroutinely conducted by national institution before exporting or importing strawberry. Thus, the current research project aimed to detect pesticides residues in strawberry fruits that were collected from major production areas in Egypt specifically from El-Beheira (El-Nubaryia, AlMahmoudia, and Bader Cities), El-Minofyia, and Ismailyia Governorates.

\section{MATERIALS AND METHODS}

\section{Chemicals and pesticide standards}

Pesticides reference standards of $>99 \%$ purity (Aldrin (10; LOQ $\mu \mathrm{g} \mathrm{Kg}{ }^{-1}$ ), Atrazine (10), Azinophosmethyl (20), $\alpha$-BHC (15), $\Delta$-BHC (10), $\gamma$-BHC (25), Boscalid (25), Bromuconazole (30), Butralin (20), Cadusafos (50), Chlorfluazuron (50), Chlorpyrifos (10), Chlorothalonil (25), Cyfluthrin (15), $\lambda$-Cyhalothrin (10), Cypermethrin (25), pp-DDD (20), pp-DDE (10), pp-DDT (10), Deltamethrin (15), Diazinon (10), Difenoconazole (20), Dimethoate (50), Dieldrin (5), Endosulfan (15), Endrin (50), Ethoprophos (5), Esfenvalerate (10), Ethion (5), Fenamiphos (15), Fenarimol (10), Fenpropathrin (25), Heptachlor (10), Heptachlor-epoxide (10), Malathion (10), Methoxychlor (25), Myclobutanil (15), Propiconazole (15), Pendimethalin (50), Permethrin (10), Phenthoate (15), Pirimiphos-methyl (10), Profenofos (15), Prothiophos (10), Pyridaben (10), Quinalophos (15), Tebuconazole (15), Thiamethoxam (50), Thiocyclam (25), and Triazophos (10)) were purchased from Cornell Lab, Cairo, Egypt. Stock solutions of $100 \mu \mathrm{gmL}^{-1}$ were prepared and working standard pesticide mixtures of50 and $10 \mu \mathrm{gmL}^{-1}$ were prepared in acetonitrile $(\mathrm{MeCN})$. Triphenyl phosphate (TPP), MeCN, acetone, glacial acetic acid, and QuEChERS extraction and dispersive SPE clean-up kits (Agilent Technologies catalogue \# 5982-0650 and 5982-5056, respectively) were purchased from Arabian Group for Integrated Technologies (AGITECH), Cairo, Egypt. Limits of quantification (LOQ) of pesticides were evaluated following the directions of US EPA (1995), EC (2004), ICH (2005), EC (2007), OCED (2007), and USP (2010) and based on a standard curve of each pesticides.

\section{Strawberry samples}

Fresh strawberry samples were collected from farms at El-Beheira (El-Nubaryia, Al-Mahmoudia, and
Bader cities), El-Minofyia, and Ismailyia Governorates from patches ready for distribution to local market. Five samples from each farm consisting of $2 \mathrm{~kg}$ each were transferred to the laboratory, thoroughly mixed, and chopped into small pieces using an electrical blender at high speed. Then three sub-samples of $10 \mathrm{~g}$ from each sample were extracted, cleaned-up, and analyzed for pesticide residues.

\section{Extraction of pesticide residues using QuEChERS method}

Extraction and cleanup were accomplished following a modified method of Anastassiades et al. (2003a) using extraction and dispersive SPE clean-up kits (Agilent Technologies catalogue \# 5982-0650 and 5982-5056, respectively). About $10 \mathrm{~g}$ of homogenized strawberry samples were transferred into $50 \mathrm{~mL}$ Falcon tube. Then $10 \mathrm{~mL}$ of $0.1 \%$ acidified $\mathrm{MeCN}$ were added. Tubes were agitated vigorously for one min by using Vortex mixer at maximum speed and four $g$ of anhydrous $\mathrm{MgSO}_{4}$ and one $\mathrm{g} \mathrm{NaCl}$ were added to each tube and mixed on Vortex mixer immediately for one min. A $50 \mu \mathrm{L}$ of TPP (internal standard) solution was mixed for 30 seconds, and extracts were centrifuged for $10 \mathrm{~min}$ at $4000 \mathrm{rpm}$ (Hermle Labortechnik $\mathrm{GmbH}$, Siemensstr.25 D-78564 Wehingen, Germany).

Approximately, one $\mathrm{mL}$ of the upper $\mathrm{MeCN}$ layer was aliquoted into $15 \mathrm{~mL}$ Falcon tubes containing $25 \mathrm{mg}$ PSA sorbent and $150 \mathrm{mg}$ anhydrous $\mathrm{MgSO}_{4}$, capped tightly and shaken by hand for $5 \mathrm{~min}$. Samples were centrifuged for $5 \mathrm{~min}$ at $4000 \mathrm{rpm}$. Samples were extracted and cleaned up in triplicates. About $0.5 \mathrm{~mL}$ of extracts was transferred into amber HPLC vials for GC/MS analysis.

\section{GC/MS running conditions}

Samples were analyzed with Agilent Technologies gas chromatography system model 7890B coupled with mass spectrometry model 5977A (GC/MS) instrument and an autosampler (Agilent, Little Falls, DE). The system was equipped with a split/splitless injection inlet, and electronic pressure control (EPC). The system was controlled by MSD Chem Station software (version F.01.03.2357) and data analysis was done by Mass Hunter GC/MS acquisition software (version B.07.03.2139). Extracts and recovery samples $(2 \mu \mathrm{l})$ were injected in the GC/MS system in splitless mode. An HP-5MS capillary column (30 m X $0.53 \mathrm{~mm}$ i.d. $0.25 \mathrm{um}$ film thickness) was used to separate the components. Helium was used as the carrier gas. Separation conditions were according to AOAC (2007) as the following program: initial column temperature set at $80^{\circ} \mathrm{C}$ for $6 \mathrm{~min}$. It was increased to $215^{\circ} \mathrm{C}$ at $15^{\circ} \mathrm{C} / \mathrm{min}$ (hold for $1 \mathrm{~min}$ ), then to $230^{\circ} \mathrm{C}$ at $5^{\circ} \mathrm{C} / \mathrm{min}$ and finally to $290^{\circ} \mathrm{C}$ at $5^{\circ} \mathrm{C} / \mathrm{min}$ (hold for 2 $\min$ ). The carrier gas was at a constant flow rate of 1.1 $\mathrm{ml} / \mathrm{min}$. The target compounds were identified by their full mass spectra scans and retention time using the total ion current as a monitor to give a Total Ion Chromatogram (TIC). The use of the full scan mode allowed the contrast of the spectrum of obtained compounds with the EI-MS library. 


\section{Quality assurance}

The quality assurance criteria were accomplished following the criteria of Codex Alimentarius committee. Calibration curves for HPLC and GC/MS systems were made at levels of $10,20,50$, and $100 \mu \mathrm{g} \mathrm{L}^{-1}$. Calibration curves were generated by plotting the relative responses of analytes (peak area of analyte/peak area of internal standard (IS)) to the relative concentration of analytes (concentration of analyte/concentration of IS). The regression equations of standards were used to calculate amounts of detected pesticides. Recovery and reproducibility were evaluated by spiking pesticide standards to fruit samples at levels of 1,10 , and $50 \mu \mathrm{g} \mathrm{L}^{-1}$ and each concentration was repeated three times. The average recovery varied between $81-102 \%$ and $88-98 \%$ for the GC/MS and HPLC, respectively.

\section{Method and machine precision}

Precision of the analytical method was confirmed through the repeatability (intra-day assay) and intermediate precision (inter-day assay) (Ermer 2005). The intra-day and inter-day precision of the method were determined by repeating the analysis of recovery samples on same day and over five consecutive days, respectively. The precision was expressed as coefficient of variation percentages $(($ mean/standard deviation $) \times 100)$. The limits of quantification (LOQs) were calculated from the signal-to-noise $(\mathrm{S} / \mathrm{N})$ ratios of the samples with the lowest concentration level of some studied pesticides.

\section{RESULTS AND DISCUSSION}

Data in Table (1) showed inter-assay and intraassay precision, which were obtained from the analysis of fortified samples with standards of pesticides. Results indicated that the intra- and inter-assay values ranged from 4.45 to 5.63 and 4.93 to $8.12 \%$, respectively. Also, the recovery percentages \pm relative standard deviation (RSD) were ranged from 91.7 \pm 4.6 to $102.1 \pm 5.2 \%$ and $92.8 \pm 6.2$ to $102.3 \pm 4.0 \%$ at 0.1 and $1 \mu \mathrm{gL}^{-1}$ levels, respectively. The results of accuracy, recovery, and RSD met acceptable criteria according to World Health Organization (2014) requirements.

Moreover, RSD values were below $20 \%$, which indicate the suitability of employed method in the analysis of pesticides residues in investigated strawberry samples. Accordingly, all data of residue analysis were corrected according to these obtained recovery percentage values.

The developed analytical method was applied for analysis of pesticides residue in strawberry fruits collected from farms at El-Beheira (El-Nubaryia, AlMahmoudia, and Bader cities), El-Minofyia, and Ismailyia Governorates. QuEChERS technique was applied for the determination of pesticide residues in strawberry fruits because of its great simplicity and sensitivity (Lorenz et al., 2014). This method covers a wide range of pesticides (polar, pH-dependent compounds), simple (no laborious steps, minimal sources of errors) and cheap (Wilkowska and Biziuk, 2011). The solvent consumption is low $(10 \mathrm{~mL}$ acetonitrile, GC- and LC-amenable) and practically no glassware is needed (Anastassiades et al., 2003b).

Table (1): Coefficients of variation (CV \%) and recovery percentages \pm relative standard deviation (RSD) values of some pesticides that were extracted from spiked strawberry samples and analyzed using GC/MS

\begin{tabular}{lcccc}
\hline \multirow{2}{*}{ Pesticide } & \multicolumn{2}{c}{$\mathbf{C V}^{*}(\mathbf{\%})$} & \multicolumn{2}{c}{ Recovery (\%) $\pm \mathbf{R S D}$} \\
\cline { 2 - 5 } Heptachlor & Intra-Assay & Inter-Assay & $\mathbf{0 . 1} \boldsymbol{\mu g L}^{-\mathbf{1}}$ & $\mathbf{1} \boldsymbol{\mu g L}^{-\mathbf{1}}$ \\
Dieldrin & 5.18 & 7.62 & $91.7 \pm 4.6$ & $92.8 \pm 6.2$ \\
p,p-DDD & 4.45 & 6.54 & $96.7 \pm 2.0$ & $99.1 \pm 1.2$ \\
p,p-DDT & 4.50 & 7.69 & $93.5 \pm 2.1$ & $95.6 \pm 1.5$ \\
Methoxychlor & 5.36 & 6.34 & $98.2 \pm 3.5$ & $102.3 \pm 4.0$ \\
Chlorpyrifos-methyl & 5.53 & 4.93 & $97.1 \pm 2.9$ & $99.3 \pm 4.0$ \\
Malathion & 4.83 & 6.84 & $97.5 \pm 3.1$ & $99.7 \pm 3.7$ \\
Chlorothalonil & 4.96 & 8.12 & $102.1 \pm 5.2$ & $101.1 \pm 2.9$ \\
Propioconazole & 5.55 & 7.91 & $98.2 \pm 4.1$ & $99.0 \pm 3.4$ \\
L-Cyhalothrin & 4.93 & 6.25 & $94.5 \pm 3.6$ & $97.0 \pm 5.7$
\end{tabular}

*Inter- and intra-assay precision data obtained from the analysis of the concentrations of each standard pesticide in extracts of fortified strawberry samples

Results presented in Table (2) showed the residue levels of the detected pesticides in strawberry samples, which collected from different places in
Egypt. These results indicated that boscalid, p,p-DDD, and propiconazole pesticides were detected in strawberry samples from Bader city at 5, 0.104, and 
$0.048 \mathrm{mgKg}^{-1}$, respectively. Endrin and propiconazole pesticides were detected in samples from Al-Minofyia city at 0.098 and $0.038 \mathrm{mgKg}^{-1}$, respectively. Whereas, Propiconazole was found in strawberry samples collected from all five locations under investigation at levels less than the MRL according to European Union (EU); $0.01,0.05,0.01$, and $6.0 \mathrm{mgKg}^{-1}$ ofendrin, p,pDDD, propiconazole, and boscalid, respectively. These results were in agreement with Chen et al. (2007) who determined residue of boscalid in cucumber with $\mathrm{GC}-$ ECD and Hiemstra and De-Kok (2007) whom reported a multi-residue method for targeted analysis of pesticides (including boscalid) in crops using liquid chromatography-tandem mass spectrometry. Although the absence of DDT in all samples of strawberry, its metabolite p,p-DDD was reported in great concentration in Bader city. This may be due to the different mechanisms of degradation such as microbial effect and oxidation (Matsumura et al., 1972), photoionization, electron transfer (Bowma and Sans, 1980) (Laymann et al., 1990) and aerobic biodegradation.

Table (2): Limits of Quantitation (LOQ), maximum residue limits (MRLs) according to the European Codex Alimentarius guidelines, and levels of detected pesticides $\left(\mathrm{mgKg}^{-1}\right)$ in strawberry samples collected from different places in Egypt using GC-MS

\begin{tabular}{llllllll}
\hline Pesticide & LOQ & MRLs & BA & NU & MA & ME & IS \\
\hline Boscalid & 0.025 & 3.000 & 5.000 & - & - & - & - \\
Endrin & 0.050 & 0.050 & - & - & - & 0.098 & - \\
pp-DDD & 0.020 & 0.200 & 0.104 & - & - & - \\
Propiconazole & 0.015 & 0.100 & 0.048 & 0.060 & 0.022 & 0.038 & 0.020 \\
\hline
\end{tabular}

Bader (BA), El-Nubaryia (NU), Al-Mahmoudia (MA), El-Minofyia (ME), and Ismailyia (IS) cities in Egypt

\section{CONCLUSIONS}

Pesticides residue levels of p,p-DDD, Endrin, propiconazole, and boscalid in all strawberry samples were less than the permissible maximum residue limit (MRL) compared to the proposed by Standards of European Union. Therefore, no health risk associated with human consumption of strawberry from studied locations.

\section{ACKNOWLEDGEMENT}

The authors would like to thank the Pesticide Residue Analysis and Toxicity Laboratory, Faculty of Agriculture, Damanhour University for running GCMS analysis.

\section{REFERENCES}

Ahmed, M. T., S. Greish, S. M. Ismail, Y. Mosleh, N. M. Loutfy and A. El Doussouki (2014). Dietary Intake of Pesticides Based on Vegetable Consumption in Ismailia, Egypt: A Case Study. Hum Ecol Risk Assess., 20: 779788. doi: 10.1080/10807039.2013.775893

Anastassiades, M., S. J. Lehotay and F. J. Schenck (2003a). Fast and Easy Multiresidue Method Employing Acetonitrile Extraction/Partitioning and Dispersive SolidPhase Extraction for the Determination of Pesticide Residues in Produce. J AOAC Int, $86: 412-431$.

Anastassiades, M., S. J. Lehotay and F. J. Schenck (2003b) Fast and Easy Multiresidue Method Employing Acetonitrile Extraction/Partitioning and \&quot; Dispersive
Solid-Phase Extraction \& quot; for the Determination of Pesticide Residues in Produce.

Anastassiades, M., S. J. Lehotay, D. Štajnbaher and F. J. Schenck (2003c). Fast and Easy Multiresidue Method Employing Acetonitrile Extraction/Partitioning and \&quot; Dispersive Solid-Phase Extraction \&quot; for the Determination of Pesticide Residues in Produce. J AOAC Int, 86: 412-431.

AOAC (2007). AOAC Official Method 2007 . 01 Pesticide Residues in Foods by Acetonitrile Extraction and Partitioning with Magnesium Sulfate, 1-9. doi: 10.1.04

Belitz, H-D, W. Grosch and P. Schieberle (2009). Food Chemistry, 4th revise. Springer Berlin Heidelberg.

Bolanos, P. P., J. L. F. Moreno, D. D. Shtereva, A. G. Frenich and J. L. M. Vidal (2007). Development and validation of a multiresidue method for the analysis of 151 pesticide residues in strawberry by gas chromatography coupled to a triple quadrupole mass analyzer. Rapid Commun Mass Spectrom, 21:22822294. doi: $10.1002 / \mathrm{rcm}$

Bowma, B. T. and W. W. Sans (1980). Stability of parathion and DDT in dilute iron solution. Environ Sci Heal B, 233:233-246.

Chen, M., J. Huang and H. Chien (2007). Residue analysis of fungicide boscalid in cucumbers following applications of boscalid 50\% water dispersible granule. Food Drug Anal, 151:174177.

Ermer, J. (2005). Method Validation in Pharmaceutical Analysis Edited by Related Titles from Wiley- 
VCH: LC/MS Applications in Drug Development Reference Materials for Chemical Analysis, 83.

FAO (2018). Strawbery Production Statistics. http://www.fao.org/faostat/en/\#data/QC.

Fernandes, V. C., S. J. Lehotay, L. Geis-asteggiante, H. Kwon, H. G. J. Mol, H. van der Kampf, N. Mateusb, V. F. Dominguesa and C. DelerueMatos (2014). Analysis of pesticide residues in strawberries and soils by GC-MS/MS, LCMS/MS and two- dimensional GC-time-offlight MS comparing organic and integrated pest management farming. Food Addit Contam 31:262-270.doi: 10.1080/19440049.2013.865842

Frenich, A. G., J. M. Vidal, E. Pastor-Montoro and R. Romero-González (2008). High-throughput determination of pesticide residues in food commodities by use of ultra-performance liquid chromatography-tandem mass spectrometry. Anal Bioanal Chem., 390: 947959. doi: 10.1007/s00216-007-1746-5.

Hiemstra, M. and A. De-Kok (2007). Comprehensive multi-residue method for the target analysis of pesticides in crops using liquid chromatography-tandem mass spectrometry. Chromatogr A, 1154: 3-25.

Jardim, A. N. O. and E. D. Caldas (2012). Brazilian monitoring programs for pesticide residues in food - Results from 2001 to 2010. Food Control 25:607-616.doi: 10.1016/j.foodcont.2011.11.001

Laymann, W. J., W. F. Reehl and D. H. Rosenblatt (1990). Handbook of Chemical Property Estimation Methods. Amer. Chem. Soc. USA. Washington D. C

Lehotay, S. J. (2011). QuEChERS Sample Preparation Approach for Mass Spectrometric Analysis of Pesticide Residues in Foods. In: Zweigenbaum J (ed) Mass Spectrometry in Food Safety: Methods and Protocols, Methods in Molecular Biology. Springer Science+Business Media, LLC 2011, pp 6591.

Looser, N., D. Kostelac, E. Scherbaum, M. Anastassiades and H. Zipper (2006). Pesticide residues in strawberries sampled from the market of the federal state of BadenWürttemberg in the period between 2002 and 2005. J fur Verbraucherschutz und Leb., 1: 135-141. doi: 10.1007/s00003-006-0022-5.

Lorenz, J. G., L. L. F. Costa, E. A. Suchara and E. S. Sant'Anna (2014). Multivariate Optimization of the QuEChERS-GC-ECD Method and Pesticide Investigation Residues in Apples, Strawberries, and Tomatoes Produced in Brazilian South. J Braz Chem Soc., 25: 15831591. doi: $10.5935 / 0103-5053.20140143$

Malhat, F. M., N. M. Loutfy and W. Thabet (2014). Dissipation Profile and Human Risk Assessment of Pyrimethanil Residues in Cucumbers and Strawberries. J Heal Pollut., 4: 36-41. doi: 10.5696/2156-9614-4-7.36
Matsumura, M. M., S. P. Margulius and A. M. Saligman (1972). Environmental Toxicology of pesticides.

Saber, A. N., F. M. Malhat, H. M. A. Badawy and D. A. Barakat (2016). Dissipation dynamic, residue distribution and processing factor of hexythiazox in strawberry fruits under open field condition. Food Chem., 196: 1108-1116. doi: 10.1016/j.foodchem.2015.10.052

Safi, J. M., N. S. Abou-Foul, Y. Z. El-Nahhal, A. H. El-Sebae (2002). Monitoring of pesticide residues on cucumber, tomatoes and strawberries in Gaza Governorates, Palestine. Nahrung/Food, 46: 34-39.

Schreiber, A., O. Cabrices and W. E. Brewer (2013). Automated Sample Preparation and Analysis Workflows for Pesticide Residue Screening in Food Samples using DPX- QuEChERS with LC-MSMS.

Sójka, M., A. Miszczak, P. Sikorski, K. Zagibajlło, E. Karlińska and M. Kosmala (2015). Pesticide residue levels in strawberry processing byproducts that are rich in ellagitannins and an assessment of their dietary risk to consumers. NFS J 1: 31-37. doi: 10.1016/j.nfs.2015.09.001

Ueno, E., H. O. I. Saito and H. Matsumoto (2003). Determination of Nitrogen- and PhosphorusContaining Pesticide Residues in Vegetables by Gas Chromatography with NitrogenPhosphorus and Flame Photometric Detection after Gel Permeation Chromatography and a Two-Step Minicolumn Cleanup. J AOAC Int., 86: 1241-1251.

Wilkowska, A. and M. Biziuk (2011). Determination of pesticide residues in food matrices using the QuEChERS methodology. Food Chem., 125: 803-812. doi: 10.1016/j.foodchem.2010.09.094

World Health Organization (2014). Harmonization Project Document 11 Guidance document on evaluating and expressing uncertainty in hazard characterization. World Heal Organ $\mathrm{xx}+$ 171. doi: ISBN 9789241507615

Zalom, F. G., D. V. Shaw and K. D. Larson (2006). Strawberry Insects and Mites in California: Ecology and Control. Encycl. Pest Manag., 13.

\section{Conflict of Interest}

The authors declare no conflict of interest.

\section{Co-Authors Contributions}

Y.M.M.S.: proposed the research problem, collected strawberry samples, extracted the samples for GC-MS analysis, and revised the manuscript, E.E.N.E.: proposed the research problem, run the quality control samples in GC-MS equipment, and wrote the manuscript, and A.M.K.N.: proposed the research problem, conducted GC-MS analyses, run statistical analysis of results, and wrote and submitted the manuscript. 


\section{دراسة متبقيات المبيدات في عينات الفراولة المجمعة من أكثر المحافظات المصرية إنتاجا

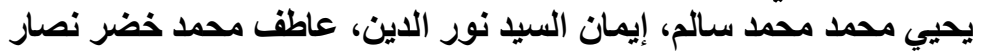

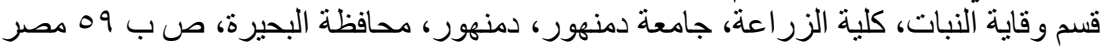

تم جمع عينات الفراولة من أماكن الإنتاج والتسويق بكل من محافظات البحيرة (مدن: النوبارية ، بدر ، المحمودية) و المنوفية

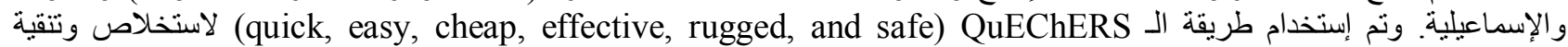

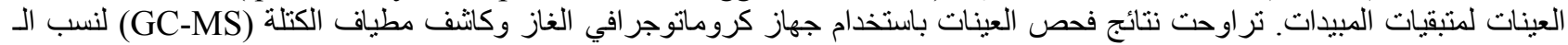
Recovery \pm RSD

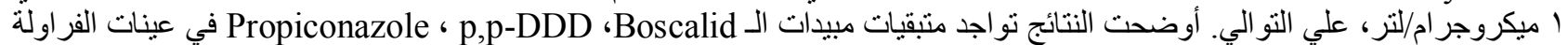

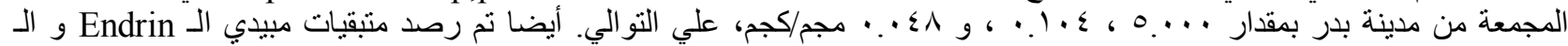

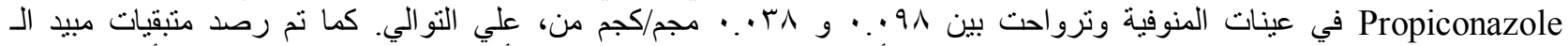

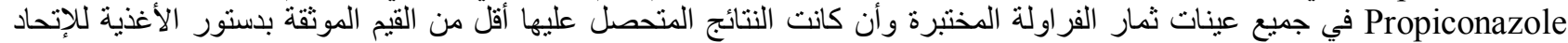
الأوروبي EU-MRLs مما يوضح أمان وسلامة الاستهلاك الغذائي للفرو الة المنو اجدة في الأسواق المصرية. 